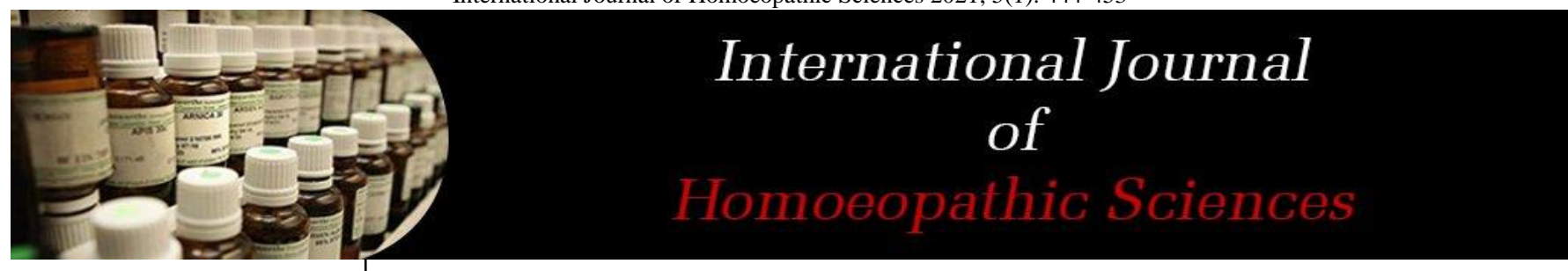

E-ISSN: $2616-4493$ P-ISSN: 2616-4485 www.homoeopathicjournal.com IJHS 2021; 5(1):444-453

Received: 25-12-2020

Accepted: 29-01-2021

Bikash Biswas

BHMS, MD (PGT 2 ${ }^{\text {nd }}$ Year), Department of Case Taking and Repertory, Mahesh Bhattacharyya Homoeopathic Medical College and Hospital, Howrah, West Bengal, India

Sanjukta Mandal

BHMS, MD (PGT $3^{\mathrm{RD}}$ Year), Department of Homoeopathic Materia Medica, Mahesh Bhattacharyya Homoeopathic Medical College and Hospital, Howrah, West Bengal, India

Nilanjan Tarafdar BHMS, MD (PGT 2 ${ }^{\text {nd }}$ Year), Department of Homoeopathic Materia Medica, Mahesh

Bhattacharyya Homoeopathic Medical College and Hospital, Howrah, West Bengal, India

Corresponding Author: Bikash Biswas BHMS, MD (PGT 2nd Year), Department of Case Taking and Repertory, Mahesh Bhattacharyya Homoeopathic Medical College and Hospital, Howrah, West Bengal, India

\section{Covid 19 sequele-neuropsyciatric disorders and homoeopathy}

\author{
Bikash Biswas, Sanjukta Mandal and Nilanjan Tarafdar
}

DOI: https://doi.org/10.33545/26164485.2021.v5.i1g.351

Abstract

SARS Cov-2 has impacted the life of people worldwide since December 2019. The majority of people have suffered from respiratory complaints along with tastelessness and anosmia. Apart from these symptoms, long continued quarantine, social deprivement, distancing, unemployment, virtual communication made people more anxious towards this disease. This resulted in numerous neuropsychiatric complaints among people, during this epidemic. the major health issues reported post COVID were anxiety, stress, insomnia, depression, PTSD, fastidiousness, forgetfulness, despair, melancholy, indifference, irritibility, anger, apprehensiveness, restlessness, suicidal tendencies among frontline workers, children, old aged people addressed with these. Homoeopathy can play a major role in the treatment of these neuropsychiatric complaints, as homoeopathy based on true fundamentals, philosophy, with proper anamnesis of each patient. Stallwarts like kent strongly believed in treatment through mental generals. In modern life most of the people suffer from psyco-somatic disorder, which typically belongs to lifestyle disorders. Regarding this epidemic situation, homoeopathy is the only safe and surest treatment option in this mental health burden arising from SARS Cov-2.

Keywords: SARS CoV-2, neuropsychiatry, homoeopathy

\section{Introduction}

COVID-19 has impacted the mental health of people around the world ${ }^{[1]}$. Emerging evidence shows neural spread of covid -19 (novel coronavirus), such as Delirium encephalopathy, olfactory disturbences, acute behavioral changes, headache and cerebrovascular accidents are its common neuropsychiatric complications ${ }^{[2]}$.

\section{AIM}

To improve homoeopathic treatment regarding this pandemic in the field of neuropsychiatric complication of COVID-19

Causes of mental health deterioration in covid-19

- Social distancing ${ }^{[3]}$.

- $\quad$ Socially excluded ${ }^{[3]}$.

- Frontline workers (doctors, nurses, other health workers) ${ }^{[3]}$.

- Insufficient capacity to give self-care ${ }^{[3]}$

- $\quad$ Excess use of alcohol, smoking ${ }^{[3]}$.

\section{Neuropsychiatric manifestations of covid-19}

The central were commonest, with dizziness and headache being most prevalent. Dysgeusia, anosmia and muscle pain were most common among the peripheral symptoms. Anxiety, depression and delirium were the common psychiatric manifestations. The neurological symptoms had direct relation with the severity of the illness, serum antibody titer and blood lymphocyte counts ${ }^{[4]}$.

\section{Possible Neupsychiatric Sequale Covid -19 Impact on Children}

Academics have reported that for many children who were separated from caregivers during the pandemic, it may place them into a state of crisis, and those who were isolated or quarantined during past pandemic disease are more likely to develop acute stress disorders, adjustment disorders and grief, with $30 \%$ of children meeting the clinical criteria for PTSD [5]. 
School closures also caused anxiety for students with special needs as daily routines are suspended or changed and all therapy or social skills groups also halted. Others who have incorporated their school routines into coping mechanisms for their mental health, have had an increase in depression and difficulty in adjusting back into normal routines.

\section{Impact on medical workers and medical personnel}

Many medical staff in China refused psychological interventions even though they showed sign of distress by; excitability, irritability, unwillingness to rest and others, stating they did not need a psychologist but more rest without interruption and enough protective supplies. They also stated using the psychologists skills instead towards the patients anxiety, panic, and other emotional problems instead of having the medical staff treat these issues ${ }^{[6]}$.

Delirium and Confusional States: Impaired sensorium ranging from mild drowsiness to delirium ${ }^{[7]}$.

Dysfunction of olfaction and taste sensation: During the SARS outbreak, studies have shown its affinity for the nasal ciliary epithelium ${ }^{[7]}$.

\section{Post-traumatic stress disorder}

There has been a particular concern for sufferers of posttraumatic stress disorder, as well as the potential for medical workers and COVID-19 patients to develop PTSD-like symptoms $[8,9,10]$.

\section{Obsessive compulsive disorder}

There has been a heightened concern for individuals suffering from obsessive-compulsive disorder, especially in regards to long-term consequences ${ }^{[11,12]}$. Fears regarding infection by the virus, and public health tips calling for hand-washing and sterilization are triggering related compulsions in some OCD sufferers ${ }^{[13]}$. Some OCD sufferers with cleanliness obsessions are noticing their greatest fears realized ${ }^{[14,15]}$. Amid guidelines of social- distancing, quarantine, and feelings of separation, some sufferers are seeing an increase in intrusive thoughts, unrelated to contamination obsessions ${ }^{[16,17]}$. Especially in regards to long term consequences. Fears regarding infection by the virus, and public health tips calling for hand washing and sterilization are triggering OCD compulsions.

\section{Suicidal tendencies}

COVID - 19 pandemic has been followed by a concern for a potential spike in suicide. Due to social distancing, fear, unemployment, \& financial factors.

China: on shanghai district reported that there have been 14 cases of suicide by school students so far this year. Since the central government concern the heightened post - lockdown anxiety as domestic media report a spate of suicide by young people ${ }^{[18]}$.

India: there are reports of people committing suicide after not being able to access alcohol during the lockdown associated with COVID-19 pandemic in India ${ }^{[19]}$.

United States: in us there was almost more than 90 cases were reported of suicide, due to prolong isolation, and stress disordres, Life style, over use of alcohol etc. ${ }^{[20]}$

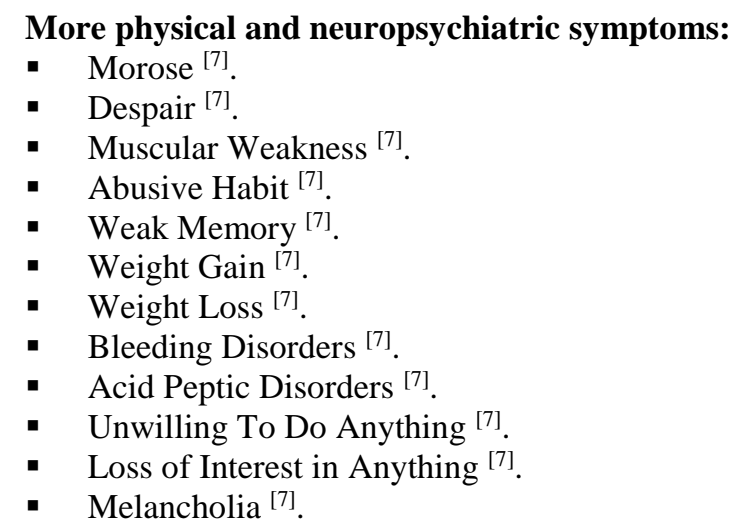

\section{More physical and neuropsychiatric symptoms:}

- Muscular Weakness ${ }^{[7]}$

- Abusive Habit ${ }^{[7]}$

- Weak Memory [7]

- Weight Gain ${ }^{[7]}$.

- Weight Loss ${ }^{[7]}$.

- Bleeding Disorders ${ }^{[7]}$.

- Acid Peptic Disorders ${ }^{[7]}$

- Unwilling To Do Anything [7]

- Melancholia ${ }^{[7]}$

Table 1: Homoeopathic Medicines and their Mode of Action

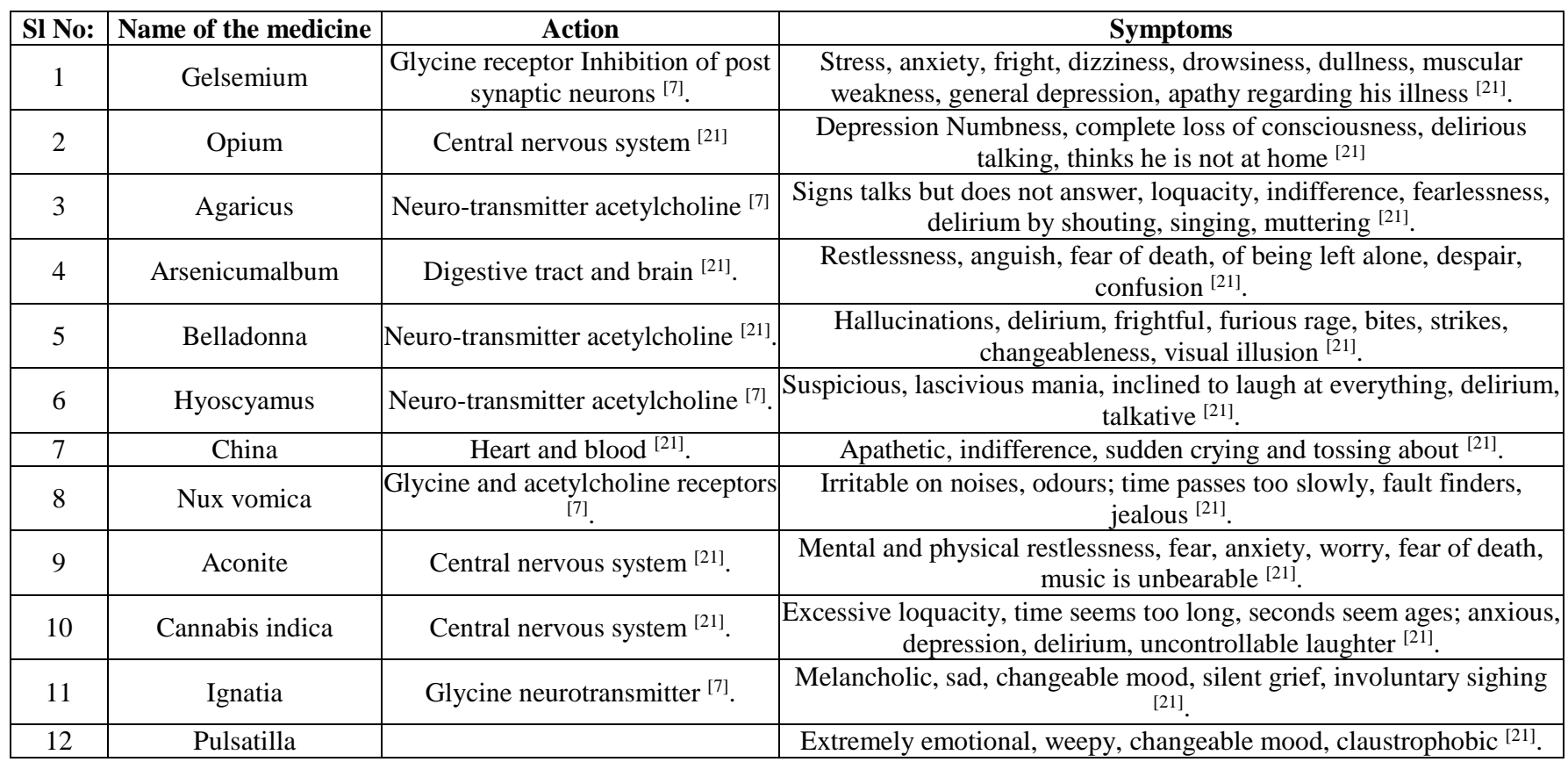




\begin{tabular}{|c|c|c|c|}
\hline 13 & Capsicum anum & Sympathetic nervous system ${ }^{[7]}$. & $\begin{array}{l}\text { Homesickness, sleeplessness, wants to be left alone, delirium, } \\
\text { disposition to suicide }{ }^{[21]} \text {. }\end{array}$ \\
\hline 14 & Anacardium orientale & Blood ${ }^{[21]}$. & $\begin{array}{c}\text { Indifference, hallucination, melancholy, hypochondriasis, suspicious, } \\
\text { easily offended, senile dementia, fixed idea }{ }^{[21]} \text {. }\end{array}$ \\
\hline 15 & Stramonium & Neuro-transmitter acetylcholine ${ }^{[7]}$. & $\begin{array}{c}\text { Loquacious, rapid changeable mood, violent and lewd, delusions about } \\
\text { his identity, religious mania, desire to escape }{ }^{[21]} \text {. }\end{array}$ \\
\hline 14 & Coffea cruda & Central nervous system ${ }^{[21]}$. & $\begin{array}{c}\text { Nervous, restlessness, neuralgia in every part, irritable, acute senses, } \\
\text { anguishness }{ }^{[21]} \text {. }\end{array}$ \\
\hline 15 & Sepia & Androgen hormone receptor ${ }^{[7]}$. & $\begin{array}{l}\text { Indifference, averse to occupation, irritable, dreads to be alone, } \\
\text { indolent, very sad, suicidal thoughts }{ }^{[21]} \text {. }\end{array}$ \\
\hline 16 & Natrum muriaticum & Systemic ${ }^{[21]}$. & $\begin{array}{c}\text { Irritable, wants to cry alone, depressed, silent grief, over sensitiveness, } \\
\text { awkward, hasty }{ }^{[21]} \text {. }\end{array}$ \\
\hline 17 & Aurum metallicum & Blood and CNS ${ }^{[21]}$. & $\begin{array}{l}\text { Hopeless, despondent, great desire to commit suicide, great fear of } \\
\text { death, anthrophobia, over sensitiveness, irritable }{ }^{[21]} \text {. }\end{array}$ \\
\hline
\end{tabular}

\section{Mechanism of action of homoeopathic medicine}

Gelsemium: Chief Alkaloid: Gelsemine (C20H22N2O2) IUPAC name: 3-ethanyl-1-methyl-2,3,3a,7,8,8a-hexahydro1h,5h-spiro[3,8,5-(ethane $\left[\begin{array}{lll}1, & 1, & 2\end{array}\right]$ triyl) oxepino[4,5-b] pyrrole-4,3'-indol]-2'(1'h)-one ${ }^{[22]}$.

\section{Mechanism of action}

It has generally potent activity as an agonist of the mammalian glycine receptor, the activation of which leads to an inhibitory postsynaptic potential in neurons following chloride (Cl-) ion influx and systemically to muscles relaxation of varying intensity and deleterious effect. Despite its danger and toxicity, recent pharmacological research has suggested that the biological activities of this compound may offer opportunities for developing treatments related to Xenobiotic- or diet induced oxidative stress, and of anxiety and other conditions, with ongoing research including attempts to identify safer derivatives and analogs to make use of Gelsemine's beneficial effects ${ }^{[52]}$.

Opium: Chief Alkaloid: a) Morphine b) Codeine c) Thebaine and Papaverine Morphine (C17H19NO3) IUPAC name: (4R,4aR,7S,7aR,12bS)-3-Methyl-2,3,4,4a,7,7ahexahydro-1H-4,4a,7,7ahexahydro-1H-4,12-

methanobenzofuro[3,2-e] isoquinoline-7,9-diol

Mechanism of action: morphine is a pain medication of the opiate family that is found naturally in a number plants and animals including ${ }^{[23]}$ humans It acts directly on the central nervous system (CNS) to decrease the feeling of pain. ${ }^{[23]}$ Morphine interacts predominantly with the $\mu$ - $\delta$-opioid receptor heteromer ${ }^{[24]}$. The $\mu$ - binding sites are discretely distributed in the human brain, with high densities in the posterior amygdala, hypothalamus, thalamus, nucleus caudatus, putamen and certain cortical areas. They are also found on the terminal axons of primary afferents within laminae I and II (substantia gelatinosa) of the spinal cord and in the spinal nucleus of the trigeminal nerve ${ }^{[24]}$. Morphine is a phenanthrene opioid receptor agonist - its main effect is binding to and activating the $\mu$-opioid receptor (MOR) in the central nervous system. Its intrinsic activity at the MOR is heavily dependent on the assay and tissue being tested; in some situations it is a full agonist while in others it can be a partial agonist or even antagonist [25]. In clinical settings, morphine exerts its principal pharmacological effect on the central nervous system and gastrointestinal tract. Its primary actions of therapeutic value are analgesia and sedation. Activation of the MOR is associated with analgesia, sedation, euphoria, physical dependence, and respiratory depression. Morphine is also a $\kappa$-opioid receptor (KOR) and Sopioid receptor (DOR) agonist. Activation of the KOR is associated with spinal analgesia, miosis (pinpoint pupils), and psychotomimetic effects. The DOR is thought to play a role in analgesia ${ }^{[24]}$.

Agaricus: Chief alkaloid: Muscarine (C9H20NO2 +) IUPAC name: 2,5-Anhydro-1,4,6-trideoxy-6(trimethylammonio)-D-ribo-hexitol.

Mechanism of action: Muscarine mimics the action of the neurotransmitter acetylcholine by agonising muscarinic acetylcholine receptors. These receptors were named after muscarine, to differentiate them from the other acetylcholine receptors (nicotinic receptors), which are comparatively unresponsive to muscarine. There are 5 different types of muscarinic receptors M1, M2, M3, M4 and M5. Most tissues express a mixture of subtypes. The M2 and M3 subtypes mediate muscarinic responses at peripheral autonomic tissues. M1 and M4 subtypes are more abundant in brain and autonomic ganglia. The odd numbered receptors, M1, M3 and M5, interact with Gq proteins to stimulate phosphoinositide hydrolysis and the release of intracellular calcium. Conversely, the even numbered receptors, M2 and M4, interact with Gi proteins to inhibit adenylyl cyclase, which results in a decrease of intracellular concentration of cyclic adenosine monophosphate (cAMP) ${ }^{[7]}$.

Arsenicum Album: In homoeopathy arsenicum album is a solution prepared by diluting aqueous arsenic trioxide generally until there is little amount of arsenic remaining in individual doses. Arsenic trioxide was approved for medical use in the United States in $200{ }^{[26]}$. It is on the World Health Organization's List of Essential Medicines [27]. Arsenic Trioxide (As2O3) IUPAC name: Diarsenic trioxide. Toxicological Symptoms: Arsenic trioxide is readily absorbed by the digestive system: toxic effects are also well known upon inhalation or upon skin contact. The first symptoms of acute arsenic poisoning by ingestion are digestive problems: vomiting, abdominal pains, diarrhea often accompanied by bleeding. Sub-lethal doses can lead to convulsions, cardiovascular problems, inflammation of the liver and kidneys and abnormalities in the coagulation of the blood. These are followed by the appearance of characteristic white lines (Mees' lines) on the nails and by hair loss. Lower doses lead to liver and kidney problems and to changes in the pigmentation of the skin. Even dilute solutions of arsenic trioxide are dangerous on contact with the eyes. Chronic arsenic poisoning is known as arsenicosis. This disorder affects workers in smelters, in populations 
whose drinking water contains high levels of arsenic (0.3$0.4 \mathrm{ppm}$ ), and in patients treated for long periods with arsenic-based pharmaceuticals. Long-term ingestion of arsenic trioxide either in drinking water or as a medical treatment can lead to skin cancer. Reproductive problems (high incidences of miscarriage, low birth weight, congenital deformations) have also been indicated in one study of women exposed to arsenic trioxide dust as employees or neighbours of a copper foundry.

Belladonna: Chief alkaloid: Tropane (C8H15N) IUPAC name: N-Methyl-8-azabicyclo[3.2.1] octane Mechanism of Action: Tropane alkaloids have pharmacological properties and can act as anticholinergics or stimulants. Anticholinergics (anticholinergic agent) are a group of substances that blocks the action of the neurotransmitter called acetylcholine $(\mathrm{ACh})$ at synapses in the central and peripheral nervous system ${ }^{[28]}$. These agents inhibit the parasympathetic nervous system by selectively blocking the binding of $\mathrm{ACh}$ to its receptor in nerve cells. The nerve fibers of the parasympathetic system are responsible for the involuntary movement of smooth muscles present in the gastrointestinal tract, urinary tract, lungs, and many other parts of the body ${ }^{[29]}$. Anticholinergics are classified according to the receptors that are affected: a) Antimuscarinic agents operate on the muscarinic acetylcholine receptors. The majority of anticholinergic drugs are antimuscarinics. b) Antinicotinic agents operate on the nicotinic acetylcholine receptors. The majority of these are non-depolarising skeletal muscle relaxants for surgical use that are structurally related to curare. Several are depolarizing agents.

Hyoscyamus niger: Chief alkaloid: hyoscyamine (C17H23NO3) IUPAC name: (S)-(1R,3r,5S)-8-methyl-8azabicyclo[3.2.1] octan-3-yl 3-hydroxy-2-phenylpropanoate

Mechanism of action: Hyoscyamine (also known as daturine or duboisine) is a naturally occurring tropane alkaloid and plant toxin. It is the levorotary isomer of atropine (third of the three major nightshade alkaloids) and thus sometimes known as levo-atropine. Hyoscyamine is an antimuscarinic; i.e., an antagonist of muscarinic acetylcholine receptors. It blocks the action of acetylcholine at parasympathetic sites in sweat glands, salivary glands, stomach secretions, heart muscle, sinoatrial node, smooth muscle in the gastrointestinal tract, and the central nervous system. It increases cardiac output and heart rate, lowers blood pressure and dries secretions ${ }^{[30]}$. It may antagonize serotonin ${ }^{[31]}$. At comparable doses, hyoscyamine has 98 per cent of the anticholinergic power of atropine. The other major belladonna-derived drug hyoscine (known in the United States as Scopolamine) has 92 per cent of the antimuscarinic potency of atropine ${ }^{[32]}$.

China officinalis: Chief alkaloid: cinchonine, quinidine. Quinidine: (C20H24N2O2) IUPAC name: (S)-(6-

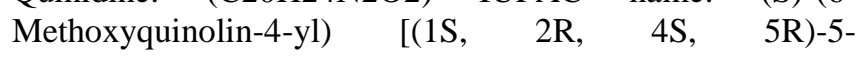
vinylquinuclidin-2-yl] methanol.

Mechanism of action: Quinidine is a medication that acts as a class I antiarrhythmic agent in the heart ${ }^{[33]}$. It is a stereoisomer of quinine, originally derived from the bark of the cinchona tree. The drug causes increased action potential duration, as well as a prolonged QT interval. Quinidine acts as a blocker of voltage-gated sodium channels [34, 35] Inhibition of the Nav1.5 channel is specifically involved in its antiarrhythmic effects as a class I antiarrhythmic agent [36]. Quinidine also blocks certain voltagegated potassium channels (e.g., Kv1.4, Kv4.2, hERG, among others) ${ }^{[38,39]}$ acts as an antimuscarinic and alpha-1 blocker ${ }^{[37]}$ and is an antimalarial ${ }^{[36]}$. The effect of quinidine on the ion channels is to prolong the cardiac action potential, thereby prolonging the QT interval on the surface ECG.

$\begin{array}{llrr}\text { Nux Vomica: Chief alkaloid: } & \text { Strychnine, Brucine. } \\ \text { Strychnine } & (\mathrm{C} 21 \mathrm{H} 22 \mathrm{~N} 2 \mathrm{O} 2) & \text { IUPAC } & \text { name: }\end{array}$ (4aR,5aS, 8aR, 13aS, 15aS, 15bR)4a,5,5a,7,8,13a,15,15a,15b,16-decahydro-2H-4,6methanoindolo[3,2,1-ij] oxepino[2,3,4-de] pyrrolo [2,3-h] quinolin-14-one

Mechanism of action: Strychnine is a neurotoxin which acts as an antagonist of glycine and acetylcholine receptors. It primarily affects the motor nerve fibres in the spinal cord which control muscle contraction. An impulse is triggered at one end of a nerve cell by the binding of neurotransmitters to the receptors. In the presence of an inhibitory neurotransmitter, such as glycine, a greater quantity of excitatory neurotransmitters must bind to receptors before there will be an action potential generated. Glycine acts primarily as an agonist of the glycine receptor, which is a ligand-gated chloride channel in neurons located in the spinal cord and in the brain. This chloride channel will allow the negatively charged chloride ions into the neuron, causing a hyperpolarization which pushes the membrane potential further from threshold. Strychnine is an antagonist of glycine; it binds noncovalently to the same receptor, preventing the inhibitory effects of glycine on the postsynaptic neuron. Therefore, action potentials are triggered with lower levels of excitatory neurotransmitters. When the inhibitory signals are prevented, the motor neurons are more easily activated and the victim will have spastic muscle contractions, resulting in death by asphyxiation. [40] [41]. Strychnine binds the Aplysia californica acetylcholine binding protein (a homolog of nicotinic receptors) with high affinity but low specificity, and does so in multiple conformations ${ }^{[41]}$.

Aconitum Napellus: Chief alkaloids: Aconitine (C34H47NO11) IUPAC name: 8-(acetyloxy)-20-ethyl$3 \alpha, 13,15$-trihydroxy-1 $\alpha, 6 \alpha, 16 \beta$-trimethoxy-4 (methoxymethyl)aconitan-14 $\alpha$-yl benzoate

Mechanism of action: Aconitine can interact with the voltage-dependent sodium-ion channels, which are proteins in the cell membranes of excitable tissues, such as cardiac and skeletal muscles and neurons. These proteins are highly selective for sodium ions. They open very fast to depolarize the cell membrane potential, causing the upstroke of an action potential. Normally, the sodium channels close very rapidly, but the depolarization of the membrane potential causes the opening (activation) of potassium channels and potassium efflux, which results in repolarization of the membrane potential. Aconitine binds to the receptor at the neurotoxin binding site 2 on the alpha-subunit of the channel protein ${ }^{[42]}$. This binding results in a sodium-ion channel that stays open longer. Aconitine suppresses the 
conformational change in the sodium-ion channel from the active state to the inactive state. The membrane stays depolarized due to the constant sodium influx (which is 101000 fold greater than the potassium efflux). As a result, the membrane cannot be repolarized. The binding of aconitine to the channel also leads to the channel to change conformation from the inactive state to the active state at a more negative voltage ${ }^{[43]}$. In neurons, aconitine increases the permeability of the membrane for sodium ions, resulting in a huge sodium influx in the axon terminal. As a result, the membrane depolarizes rapidly. Due to the strong depolarization, the permeability of the membrane for potassium ions increases fast, resulting in a potassium reflux to release the positive charge out of the cell. Not only the permeability for potassium ions but also the permeability for calcium ions increases as a result of the depolarization of the membrane. A calcium influx takes place. The increase of the calcium concentration in the cell stimulates the release of the neurotransmitter acetylcholine into the synaptic cleft. Acetylcholine binds to acetylcholine receptors at the postsynaptic membrane to open the sodium-channels there, generating a new action potential.

Cannabis indica: Chief alkaloid: Tetrahydrocannabinol (THC) IUPAC name: (6aR, 10aR)-6,6,9-Trimethyl-3pentyl-6a,7,8,10a-tetrahydro-6H-benzo [c] chromen-1-ol

Mechanism of action: THC is the principal psychoactive constituent of cannabis. Although the chemical formula for THC (C21H30O2) describes multiple isomers [44]. Dronabinol, a pharmaceutical form of THC, has been approved by the FDA as an appetite stimulant for people with AIDS and an antiemetic for people receiving chemotherapy under the trade names Marinol and Syndros [45]. The pharmaceutical formulation dronabinol is an oily and viscous resin provided in capsules available by prescription in the United States, Canada, Germany, and New Zealand. The actions of THC result from its partial agonist activity at the cannabinoid receptor $\mathrm{CB} 1(\mathrm{Ki}=10$ $\mathrm{nM}{ }^{[22]}$ ), located mainly in the central nervous system, and the $\mathrm{CB} 2$ receptor $\left(\mathrm{Ki}=24 \mathrm{nM}{ }^{[74]}\right)$, mainly expressed in cells of the immune system ${ }^{[46]}$. The psychoactive effects of THC are primarily mediated by the activation of cannabinoid receptors, which result in a decrease in the concentration of the second messenger molecule cAMP through inhibition of adenylate cyclase ${ }^{[47]}$. THC is a lipophilic molecule ${ }^{[48]}$ and may bind non-specifically to a variety of entities in the brain and body, such as adipose tissue (fat) ${ }^{[49,50]}$. THC, as well as other cannabinoids that contain a phenol group, possess mild antioxidant activity sufficient to protect neurons against oxidative stress, such as that produced by glutamate-induced excitotoxicity ${ }^{[47]}$.

\section{Veratrum album: Chief alkaloid: veratramine (C27H39NO2) IUPAC name: (3ß,23R)-14,15,16,17-} Tetradehydroveratraman-3,23-diol

Mechanism of action: In general, Veratrum alkaloids act by increasing the permeability of the sodium channels of nerve cells, causing them to fire continuously. Increased stimulation, associated with the vagus nerve, results in the Bezold-Jarisch reflex: hypotension, bradycardia and apnoea [51]. The neurotoxicity of Veratrum alkaloids derives from their effect on the sodium ion channels of nerve cells. They activate receptor site 2 of the voltage-dependent $\mathrm{Na}+$ channel in membranes by prolonging its open state ${ }^{[52]}$. The alkaloids depolarize nerves by enhancing exchange of $\mathrm{Na}+$ and $\mathrm{K}+$ across the membrane ${ }^{[53]}$.

Ignatia amara: Chief alkaloid: Strychnine, Brucine [54]. Strychnine (C21H22N2O2) IUPAC name: (4aR,5aS, 8aR, 13aS, 15aS, 15bR)4a,5,5a,7,8,13a, 15, 15a,15b,16-decahydro-2H-4,6methanoindolo[3,2,1-ij] oxepino[2,3,4-de] pyrrolo [2,3-h] quinolin-14-one

Mechanism of action: Strychnine is a neurotoxin which acts as an antagonist of glycine and acetylcholine receptors. It primarily affects the motor nerve fibres in the spinal cord which control muscle contraction. An impulse is triggered at one end of a nerve cell by the binding of neurotransmitters to the receptors. In the presence of an inhibitory neurotransmitter, such as glycine, a greater quantity of excitatory neurotransmitters must bind to receptors before there will be an action potential generated. Glycine acts primarily as an agonist of the glycine receptor, which is a ligand-gated chloride channel in neurons located in the spinal cord and in the brain. This chloride channel will allow the negatively charged chloride ions into the neuron, causing a hyperpolarization which pushes the membrane potential further from threshold. Strychnine is an antagonist of glycine; it binds noncovalently to the same receptor, preventing the inhibitory effects of glycine on the postsynaptic neuron. Therefore, action potentials are triggered with lower levels of excitatory neurotransmitters. When the inhibitory signals are prevented, the motor neurons are more easily activated and the victim will have spastic muscle contractions, resulting in death by asphyxiation ${ }^{[40,41]}$. Strychnine binds the Aplysia californica acetylcholine binding protein (a homolog of nicotinic receptors) with high affinity but low specificity, and does so in multiple conformations ${ }^{[42]}$.

Pulsatilla pratensis: Chief alkaloid: protoanemonin $\left(\mathrm{C}_{5} \mathrm{H}_{4} \mathrm{O}_{2}\right)$ IUPAC name: 5-Methylidenefuran-2-one

Mechanism of action: Protoanemonin (sometimes called anemonol or ranunculol) ${ }^{[55]}$ is a toxin found in all plants of the buttercup family (Ranunculaceae). When the plant is wounded or macerated, the unstable glucoside found in the plant, ranunculin, is enzymatically broken down into glucose and the toxic protoanemonin ${ }^{[56]}$. It is the lactone of 4-hydroxy-2,4-pentadienoic acid. Contact with a wounded plant causes itch, rashes or blistering on contact with the skin or mucosa. Ingesting the toxin can cause nausea, vomiting, dizziness, spasms, acute hepatitis, jaundice, or paralysis $[57,58,59]$. When drying the plant, protoanemonin comes into contact with air and dimerizes to anemonin, which is further hydrolysed to a non-toxic dicarboxylic acid [56, 60]. In a study it was found that antimicrobial study of protoanemonin is present ${ }^{[61]}$.

Capsicum annum: Chief alkaloid: Capsinoids, capsaicin Capsaicin (C18H27NO3) IUPAC name: (E)-N-[(4-hydroxy3-methoxyphenyl)methyl]-8-methylnon-6-enamide

Mechanism of action: Capsinoids have an estimated "hot taste threshold" which is about $1 / 1000$ that of capsaicin. 
Many health effects have been ascribed to capsaicin and capsinoids, both anecdotally and through scientific study, including anticancer, anti-inflammatory, and analgesic activities, and weight management ${ }^{[62]}$. It is anecdotally said that hot peppers help people in the tropics "cool off." This theory is consistent with the peripheral vasodilatory effect of capsaicin that has been shown to lower skin temperature in humans exposed to a hot environment ${ }^{[63]}$. Capsaicin feels hot in the mouth because it activates sensory receptors on the tongue otherwise used to detect thermal heat ${ }^{[64]}$. This receptor is called Transient Receptor Potential Vanilloid 1 (TRPV1). TRPV1 receptors are also located in the gut and in other organs ${ }^{[65]}$. Stimulation of TRPV1 receptors is known to bring about activation of the sympathetic nervous system (SNS) ${ }^{[66]}$. Capsaicin has been shown to increase fat burning in humans and animals through stimulation of the SNS [67]. Like capsaicin, capsinoids activate TRPV1 receptors ${ }^{[68]}$. Although they are not hot in the mouth. Capsinoids cannot reach the TRPV1 oral cavity receptors, located slightly below the surface in the mouth, because of structural differences from capsaicin. On the other hand, both capsaicin and capsinoids activate TRPV1 receptors in the same manner ${ }^{[69]}$. Research has indicated that the TRPV1 receptors in the gut are important for the metabolic effects of capsaicin and capsinoids ${ }^{[70]}$.

\section{Anacardium orientale}

Chief alkaloid: bioflavonoids (C30H22O12) IUPAC name: (2R,3R)-8-[(2S,3R)-5,7-dihydroxy-2-(4-hydroxyphenyl)-4oxo-2,3-dihydrochromen-3-yl]- 2-(3,4-dihydroxyphenyl)3,5,7-trihydroxy-2,3-dihydrochromen-4-one

Mechanism of action: Flavonoids are poorly absorbed in the human body (less than 5\%), then are quickly metabolized into smaller fragments with unknown properties, and rapidly excreted [71, 72]. Flavonoids have negligible antioxidant activity in the body, and the increase in antioxidant capacity of blood seen after consumption of flavonoid-rich foods is not caused directly by flavonoids, but is due to production of uric acid resulting from flavonoid depolymerization and Inflammation has been implicated as a possible origin of numerous local and systemic diseases, such as cancer [73] Cardiovascular disorders ${ }^{[74]}$ diabetes mellitus ${ }^{[75]}$ and celiac disease ${ }^{[76]}$. Excretion [71, 77]. Clinical studies investigating the relationship between flavonoid consumption and cancer prevention/development are conflicting for most types of cancer, probably because most human studies have weak designs, such as a small sample size ${ }^{[71,78]}$. There is little evidence to indicate that dietary flavonoids affect human cancer risk ${ }^{[71]}$. Among the most extensively studied of general human disorders possibly affected by dietary flavonoids, research on cardiovascular disease has not provided sufficient evidence of an effect of flavonoids, as of $2016^{[71]}$. Reviews of cohort studies in 2013 found that the studies had too many limitations to determine a possible relationship between increased flavonoid intake and decreased risk of cardiovascular disease, although a trend for an inverse relationship existed ${ }^{[71,79]}$.

Stramonium: Chief alkaloid: Tropane (C8H15N) IUPAC name: N-Methyl-8-azabicyclo [3.2.1] octane.

Mechanism of action: Tropane alkaloids have pharmacological properties and can act as anticholinergics or stimulants. Anticholinergics (Anticholinergic agent) are a group of substances that blocks the action of the neurotransmitter called acetylcholine $(\mathrm{ACh})$ at synapses in the central and peripheral nervous system ${ }^{[29]}$. These agents inhibit the parasympathetic nervous system by selectively blocking the binding of $\mathrm{ACh}$ to its receptor in nerve cells. The nerve fibers of the parasympathetic system are responsible for the involuntary movement of smooth muscles present in the gastrointestinal tract, urinary tract, lungs, and many other parts of the body [30]. Anticholinergics are classified according to the receptors that are affected:

a) Antimuscarinic agents operate on the muscarinic acetylcholine receptors. The majority of anticholinergic drugs are antimuscarinics.

b) Antinicotinic agents operate on the nicotinic acetylcholine receptors. The majority of these are nondepolarising skeletal muscle relaxants for surgical use that are structurally related to curare. Several are depolarizing agents.

Coffea cruda: Chief alkaloid: Caffeine, Putrescine, Theophylline, Trigonelline Caffeine (C8H10N4O2) IUPAC name: 1,3,7-Trimethylpurine-2,6-dione

Mechanism of action: Caffeine is a central nervous system (CNS) stimulant of the methylxanthine class ${ }^{[80]}$. It is the world's most widely consumed psychoactive drug [81]. Unlike many other psychoactive substances, it is legal and unregulated in nearly all parts of the world. There are several known mechanisms of action to explain the effects of caffeine. The most prominent is that it reversibly blocks the action of adenosine on its receptors and consequently prevents the onset of drowsiness induced by adenosine. Caffeine also stimulates certain portions of the autonomic nervous system. In the absence of caffeine and when a person is awake and alert, little adenosine is present in (CNS) neurons. With a continued wakeful state, over time adenosine accumulates in the neuronal synapse, in turn binding to and activating adenosine receptors found on certain CNS neurons; when activated, these receptors produce a cellular response that ultimately increases drowsiness. When caffeine is consumed, it antagonizes adenosine receptors; in other words, caffeine prevents adenosine from activating the receptor by blocking the location on the receptor where adenosine binds to it. As a result, caffeine temporarily prevents or relieves drowsiness, and thus maintains or restores alertness ${ }^{[82]}$.

\section{Sepia}

Source: Cuttle fish Order: Sepiida Toxicological effects: Some cuttlefish are venomous. The genes for venom production are thought to be descended from a common ancestor ${ }^{[83]}$. The muscles of the flamboyant cuttlefish (Metasepiapfefferi) contain a highly toxic, unidentified compound ${ }^{[84]}$. As lethal as that of a fellow cephalopod, the blue-ringed octopus ${ }^{[85]}$. Studies are said to indicate cuttlefish to be among the most intelligent invertebrates ${ }^{[84]}$. Cuttlefish also have one of the largest brain-to-body size ratios of all invertebrates [84]. INK: Like other marine mollusks, cuttlefish have ink stores that are used for chemical deterrence, phagomimicry, sensory distraction, and evasion when attacked ${ }^{[21]}$. Its composition results in a 
dark colored ink, rich in ammonium salts and amino acids that may have a role in phago mimicry defenses ${ }^{[21]}$. The ink can be ejected to create a "smoke screen" to hide the cuttlefish's escape, or it can be released as a pseudomorph of similar size to the cuttlefish, acting as a decoy while the cuttlefish swims away ${ }^{[21]}$.

\section{Natrum muriaticum}

Chemical formula: $\mathrm{NaCl}$ IUPAC name: Sodium chloride Toxicological symptoms: Salt poisoning typically results in a feeling of confusion and jitteriness; more severe degrees of intoxication can cause seizures and coma. Death can result if medical intervention is not forthcoming. These symptoms are generally a consequence of hypernatremiaan abnormally high sodium level in the blood ${ }^{[7]}$. Early on, the intoxicant will cause a strong feeling of thirst, followed by weakness, nausea, and loss of appetite. More severe symptoms ensue, including confusion, muscle twitching, and bleeding in or around the brain. Death results by the swelling of the brain against the skull. Drinking seawater temporarily increases blood's $\mathrm{NaCl}$ concentration, which signals the kidney to excrete sodium. However, seawater's sodium concentration is above the kidney's maximum concentrating ability. Eventually the blood's sodium concentration rises to toxic levels, removing water from cells and interfering with nerve conduction, ultimately producing a fatal seizure and cardiac arrhythmia ${ }^{[21]}$.

Aurummetallicum: Chemical formula: Au IUPAC name: gold Toxicological symptoms: Pure metallic (elemental) gold is non-toxic and non-irritating when ingested ${ }^{[21]}$ and is sometimes used as a food decoration in the form of gold leaf. - Mucocutaneous effects- most common - Dermatitis, pruritus, urticaria, stomatitis - Less common: alopecia, trophic nails - pseudocyanosis (non-blanching blue-grey skin discoloration; spares mucous membranes, may be more pronounced where sun-exposed) - Metallic taste - Diarrhea, enterocolitis (mild symptoms common, sometimes severe) • Proteinuria/membranous glomerulonephritis (common), nephrotic syndrome (rare) - Post-injection vasomotor reaction +/- anaphylaxis, syncope (rare) - Eosinophilia (common) - Cytopenias, aplastic anemia (rare) • Hepatotoxicity, pancreatitis (rare) - Encephalopathy, peripheral/cranial neuropathies (rare) • Interstitial pneumonitis (rare) ${ }^{[21]}$.

\section{Repertorial analysis}

- $\quad$ MIND, forgetful- CAN.IND., APIS., PULS., NUX.V., NAT.MUR [86]

- MIND, anger- ANAC., ARS., BRY., IGN., NUX.V [86]

- MIND, anxiety- ACON., ARS., BELL., BRY., PULS [86]

- MIND, confusion- BELL., BRY., CAN.I., NUX.V., STRYCH., NAT.M., SEP, OP ${ }^{[86]}$

- MIND, delirium-AGAR., ARS., BELL., CAN.IND., OP., HYOS., STRAM ${ }^{[86]}$

- MIND, delusion-BELL., CAN. IND., HYOS, IGN., STRAM. ${ }^{[86]}$.

- MIND, despair- ARS., COFF., HELL., IGN. ${ }^{[86]}$

- MIND, dullness- GELS., BRY., BELL., OP., SEP., NAT. M. ${ }^{[86]}$.

- MIND, fright-ACON., OP., IGN., PULS., NAT.M ${ }^{[86]}$

- MIND, fastidious-ARS., NUX.V ${ }^{[86]}$ ss
- MIND, homesickness-CAPS, CARB.AN., PHOS, AC [86]

- MIND, indifference- IGN., CHINA., HELL., OP., PULS., SEP ${ }^{[86]}$.

- MIND, irritability- ACON., APIS., BRY., CHAM., NUX., NAT-M., SEP., SRTYCH ${ }^{[86]}$.

- MIND, memory weak- CON., ARS., HELL., HYOS., SEP., VERAT ${ }^{[86]}$.

- MIND, religious-HYOS., LACH., SUIPH ${ }^{[86]}$.

- MIND, sadness-ARS., CHIN., IGN., NAT.M., SEP., VERAT ${ }^{[86]}$.

- MIND, senses acute-COFFEA., BELL., ARS., OP., NUX-V [86].

- MIND, suicide-AUR.M., CHIN., NUX.V., NAT.S ${ }^{[86]}$.

- MIND, mania-BELL., HYOS.,STRAM.,VERAT. ${ }^{[86]}$

- MIND, weary-ARS., CHIN ${ }^{[86]}$.

- NOSE, smell, diminished-ANAC., BELL., HYOS., SEP., SIL., NAT.M ${ }^{[86]}$.

- MOUTH, taste, insipid-ANAC., MERC., PULS., NAT.M ${ }^{[86]}$.

- STOMACH, appetite, capricious- BRY., CHINA ${ }^{[86]}$.

- STOMACH, appetite, diminished- ALU., PIC.AC ${ }^{[86]}$.

- STOMACH, appetite, increased- ARS., CAN.I., CHIN., PULS., VERT., NUX.V ${ }^{[86]}$.

- ANTICIPATIONS agg- ARS, GELS, MED, NAT-M, NUX-V [87].

- FASTIDIOUS- ARS, GRAPH, NUX-V ${ }^{[87]}$.

- GRIEF, sorrow- IGN, PULS, NAT-M, GELS ${ }^{\text {[87]. }}$

- SUICIDAL DISPOSITION, weary of life- ARS, AURM, NAT-M, CHIN, NUX-V, PULS, BELL, CAPS [87].

- FEAR, anxiety, fright- OPIUM, ARS, BELL, ACO, IGN, PULS ${ }^{[87]}$.

- INSAMITY, MANIA, craziness- BELL, VERT-A, OPIUM, STRAM, ARS, NUX-V, HYOS ${ }^{[87]}$.

- SLEEPLESSNESS, insomnia- ARS, BELL, COFFEA, HYOS, NUX-V, OPIUM, PULS, SEP [87].

- SENSES, SPECIAL, blunt, dulled- ANAC, HYOS, NAT-M, PULS ${ }^{[87]}$.

- TASTE, lost, wanting- ANAC, BELL, HYOS, MAGM, NAT-M, PULS ${ }^{[87]}$.

\section{Discussion}

All the medicines the $12 \mathrm{c}$ dilution does not contain only molecules of its alkaloid, rather the $12 \mathrm{c}$ dilution contain more empty shells that represent the 3Dstructure of alkaloids, and that shells are found by arrangement of alcoholic molecules. This e mpty shells reach the receptor which was being agonisted by pathological molecules, get freed as the pathological molecules freely attached due to conformational isomerism to the empty shells, thus the receptor activated by this.

\section{Conclusion}

Scientist have come up with a vaccination against the SARS Cov-2 to save millions of people, but the mental health issues are also to be taken care of.to handle the neuropsychiatric complication a number of homoeopathic medicines along with their mode of action, sphere of action and also reportorial approach has been dicussed. This discussion can prove beneficial homoeopathic physicians in treating people suffering from neuropsychiatric complication of COVID-19. 


\section{References}

1. CDC $911^{\text {th }}$ feb 2020) coronavirus disease 2019 (covid 19) centers for disease control and prevention. retrived $17^{\text {th }}$ may 2020.

www.medscape.com.

2. "Inter-Agency Standing Committee Guidelines on Mental Health and Psychosocial support" (PDF). MH Innovation. Archived (PDF) from the original 2020. Retrieved 28 March 2020.

3. Luo Yang, Chua Cher Rui; Xiong Zhonghui Ho, Roger CHo, Cyrus SH. "A Systematic Review of the Impact of Viral Respiratory Epidemics on Mental Health: An Implication on the Coronavirus Disease 2019 Pandemic". Frontiers in Psychiatry 2020. 11: 565098. doi:10.3389/fpsyt.2020.565098. PMC 7719673. PMID 33329106.

4. Liu Jia Jia Bao, Yanping Huang, Xiaolin Shi, Jie Lu, Lin. "Mental health considerations for children quarantined because of COVID-19". The Lancet Child \& Adolescent Health 2020;4(5):347-349. doi:10.1016/S2352-4642(20)30096-1. ISSN 23524642. PMC 7118598. PMID 32224303.

5. Rimmer, Abi. 2020. "Sixty Seconds on. Wobble Rooms". BMJ: m4461. doi:10.1136/bmj.m4461. ISSN 17561833. PMID 33199290. S2CID 226966877. www.wikipedia.com.

6. Turay Jr, Ismail.). "COVID-19: Social distancing may affect one's mental health, experts say". Dayton Daily News. Retrieved 2020.

7. Jain Shaili MD. "Bracing for an Epidemic of PTSD Among COVID-19 Workers". Psychology Today. Retrieved 2020.

8. "UPMC psychologist discusses mental health impact of COVID-19 on patients with PTSD, trauma". WJAC 6. Retrieved, 2020.

9. Katherine Rosman. "For Those With O.C.D., a Threat That Is Both Heightened and Familiar". The New York Times. Retrieved, 2020.

10. Fineberg NA, Van Ameringen M, Drummond L, Hollander E, Stein DJ, Geller D et al. "How to manage obsessive-compulsive disorder (OCD) under COVID19: A clinician's guide from the International College of Obsessive Compulsive Spectrum Disorders (ICOCS) and the Obsessive-Compulsive Research Network (OCRN) of the European College of Neuropsychopharmacology". Comprehensive Psychiatry. 100:152174. doi:10.1016/j.comppsych.2020 .152174. PMC 7152877. PMID 32388123

11. Pyrek, Emily. "COVID-19 proving extra challenging for people with OCD and other mental health conditions". La Crosse Tribune. Retrieved 2020.

12. Moore, Georgie. "Battling anxiety in the age of COVID-19". Australian Associated Press. Retrieved 2020.

13. Sparrow, Wendy. "'COVID-19 Is Giving Everyone A Small Glimpse Of What It's Like To Live With OCD'". Women's Health. Retrieved, 2020.

14. Welch, Craig. "Are we coping with social distancing? Psychologists are watching warily". National Geographic. Retrieved, 2020.

15. Zakarin Jordan. "A Pandemic Is Hell For Everyone, But Especially For Those With OCD". The Huffington Post. Retrieved, 2020.
16. Goh Winni Zhou, Brenda. "In post-lockdown China, student mental health in focus amid reported jump in suicides". Reuters. Retrieved, 2020.

17. Two tipplers in Kerala commit suicide upset at not getting liquor during COVID-19 lockdown". The New Indian Express. Archived from the original on Retrieved, 2020.

18. John Ann, Pirkis Jane Gunnell David. Appleby Louis. Morrissey, Jacqui. "Trends in suicide during the covid19 pandemic" 2020. BMJ. 371: m4352. doi:10.1136/bmj.m4352. ISSN 17561833. PMID 33184048. S2CID 226300218.

19. Boericke W. Pocket manual of homoeopathic materia medica and repertory, $57^{\text {th }}$ impression: 2019, Bjain publishers (p) ltd.

20. Wikipedia.com. Adi BS. Efficacy of homoeopathic medicines in chronic low back pain: a clinical study. International Journal of Alternative and Complementary Medicine 2020, 17-20.

21. "Morphine sulfate". The American Society of HealthSystem Pharmacists. Archived from the original on 2 May 2015. Retrieved, 2015.

22. Yekkirala AS, Kalyuzhny AE, Portoghese PS. "Standard opioid agonists activate heteromeric opioid receptors: evidence for morphine and [d-Ala(2)MePhe(4)- Glyol(5)]enkephalin as selective $\mu-\delta$ agonists". ACS Chemical Neuroscience. 2020;1(2):14654. doi:10.1021/cn9000236. PMC 3398540. PMID 22816017.

23. "MS-Contin (Morphine Sulfate Controlled-Release) Drug Information: Clinical Pharmacology". Prescribing Information. RxList. Archived from the original on 15 May. 4. Kelly E. "Efficacy and ligand bias at the $\mu$ opioid receptor". British Journal of Pharmacology 2007;169(7):1430-46. doi:10.1111/bph.12222. PMC 3724102. PMID 23646826

24. "Arsenic Trioxide Monograph for Professionals". Drugs.com. Retrieved, 2019.

25. World Health Organization. World Health Organization model list of essential medicines: 21st list 2019. Geneva: World Health Organization 2019. hdl:10665/325771. WHO/MVP/EMP/IAU/2019.06.

26. Clinical Pharmacology [database online]. Tampa, FL: Gold Standard, Inc.; 2009. Drugs with Anticholinergic Activity. Prescriber's Letter 2011; 18 (12):271233

27. Migirov A, Datta AR. "article-17683", Physiology, Anticholinergic Reaction, This book is distributed under the terms of the Creative Commons Attribution 4.0 International License 2020. (http://creativecommons.org/licenses/by/4.0/), which permits use, duplication, adaptation, distribution, and reproduction in any medium or format, as long as you give appropriate credit to the original author(s) and the source, a link is provided to the Creative Commons license, and any changes made are indicated., Treasure Island (FL): StatPearls Publishing, PMID 31536197, retrieved 2020-03-24

28. Edwards Pharmaceuticals, Inc; Belcher Pharmaceuticals, Inc. (May 2010), DailyMed, U.S. National Library of Medicine, retrieved January 13, 2013

29. Kapoor AK, Raju SM. Illustrated Medical Pharmacology. JP Medical Ltd. 2013, 131. ISBN 9789350906552. Retrieved January 11, 2014. 
30. Grace AA, Camm AJ. "Quinidine". N. Engl. J Med 1998;338(1):35-45. doi:10.1056/NEJM199801013380107. PMID 9414330.

31. de Lera Ruiz M, Kraus RL. "Voltage-Gated Sodium Channels: Structure, Function, Pharmacology, and Clinical Indications". J Med. Che 2015;58(18):7093118. doi:10.1021/jm501981g. PMID 25927480

32. Hugues Abriel. Cardiac Sodium Channel Disorders, An Issue of Cardiac Electrophysiology Clinics, E-Book. Elsevier Health Sciences 2015, 695. ISBN 978-0-32332641- 4.

33. Hugh Hemmings C, Talmage Egan D. Pharmacology and Physiology for Anesthesia: Foundations and Clinical Application: Expert Consult - Online and Print. Elsevier Health Sciences 2013, 451. ISBN 978-1-43771679-5.

34. Shibata K, Hirasawa A, Foglar R, Ogawa S, Tsujimoto G. "Effects of quinidine and verapamil on human cardiovascular alpha1-adrenoceptors". Circulation 1998;97(13): 1227-30. doi:10.1161/01.cir.97.13.1227. PMID 9570190

35. Laszlo Urban, Vinod Patel, Roy J Vaz.. Antitargets and Drug Safety. Wiley. Adi Bsabs, Rami Srres, Reddy E. An open clinical study on the efficacy of Withania somnifera mother tincture in the management of hyperlipidemia. International Journal of Indigenous Herbs and Drugs 2015, 303-1. 2019, P1-6. ISBN 978-3527-67367-4.

36. Stephen L. Archer; Nancy Rusch J. Potassium Channels in Cardiovascular Biology. Springer Science \& Business Media 2012, 343. ISBN 978-1-4615-1303-2.

37. Sharma RK. Consice textbook of forensic medicine \& toxicology, Elsevier, 2008

38. Waring RH, Steventon GB, Mitchell SC. Molecules of death, Imperial College Press, 2007

39. Brams M, Pandya A, Kuzmin D, Van Elk R, Krijnen L, Yakel JL et al. "A Structural and Mutagenic Blueprint for Molecular Recognition of Strychnine and dTubocurarine by Different Cys-Loop Receptors". PLOS Biology 2011;9(3):e1001034. doi:10.1371/journal.pbio.1001034. PMC 3066128. PMID 21468359

40. Gutser UT, Friese J, Heubach JF, Matthiesen T, Selve $\mathrm{N}$, Wilffert B et al. "Mode of antinociceptive and toxic action of alkaloids of Aconitum spec". Naunyn Schmiedeberg's Archives of Pharmacology 1998;357(1):39-48. doi:10.1007/p100005136. PMID 9459571

41. Benoit E. "Mécanisme(s) d'action des neurotoxinesagissant sur l'inactivation des canaux sodium activés par le potentiel de membrane" [Mechanism of action of neurotoxins acting on the inactivation of voltage-gated sodium channels]. ComptesRendus des Séances de la Société de Biologie et de SesFiliales (in French). (1998;192(3):409-36. PMID 9759381

42. "THC Chemistry by Alexander Shulgin. ". Www.druglibrary.org. Retrieved 2020-11-12.

43. "Marinol (Dronabinol)". US Food and Drug Administration. September Retrieved, 2018.

44. Pertwee RG. "The pharmacology of cannabinoid receptors and their ligands: An overview". International Journal of Obesity 2006;30:S13-S18. doi:10.1038/sj.ijo.0803272. PMID 16570099.
45. Elphick MR, Egertová M. "The neurobiology and evolution of cannabinoid signalling". Philosophical Transactions of the Royal Society B: Biological Sciences 2001;356(1407):381-408. doi:10.1098/rstb.2000.0787. PMC 1088434. PMID 11316486.

46. Rashidi H, Akhtar MT, van der Kooy F, Verpoorte R, Duetz WA. "Hydroxylation and Further Oxidation of $\Delta$ 9-Tetrahydrocannabinol by Alkane Degrading Bacteria". Appl Environ Microbiol 2009;75(22):71357141. doi:10.1128/AEM.01277- 09. PMC 2786519. PMID 19767471. $\triangle 9$-THC and many of its derivatives are highly lipophilic and poorly water soluble. Calculations of the n-octanol-water partition coefficient $(\mathrm{Ko} / \mathrm{w})$ of $\Delta 9$-THC at neutral $\mathrm{pH}$ vary between 6,000 , using the shake flask method, and $9.44 \times 106$, by reverse-phase high-performance liquid chromatography estimation. 28.

47. Ashton $\mathrm{CH}$. "Pharmacology and effects of cannabis: a brief review". Br J Psychiatry 2001;178(2):101-106. doi:10.1192/bjp.178.2.101. PMID 11157422. Because they are extremely lipid soluble, cannabinoids accumulate in fatty tissues, reaching peak concentrations in 4-5 days. They are then slowly released back into other body compartments, including the brain. Within the brain, THC and other cannabinoids are differentially distributed. High concentrations are reached in neocortical, limbic, sensory and motor areas.

48. Huestis MA. "Human cannabinoid pharmacokinetics". Chemistry \& Biodiversit 2007;4(8):1770-804. doi:10.1002/cbdv.200790152. PMC 2689518. PMID 17712819. "THC is highly lipophilic and initially taken up by tissues that are highly perfused, such as the lung, heart, brain, and liver."

49. Schep Leo J, Schmierer David M, Fountain John S. "Veratrum Poisoning". Toxicological Reviews 200606-01;25(2):73-78. doi:10.2165/00139709-20062502000001. ISSN 1176-2551. PMID 16958554. S2CID 42124743.

50. Ujvary Istvan, Eya Bryan K, Grendell Richard L, Toia, Robert F, Casida, John E. "Insecticidal activity of various 3-acyl and other derivatives of veracevine relative to the veratrum alkaloids veratridine and cevadine". Journal of Agricultural and Food Chemistry. 1991;39(10):1875-1881. doi:10.1021/jf00010a039. ISSN 0021-8561.

51. Papahadjopoulos D. "Studies on the mechanism of action of local anesthetics with phospholipid model membranes". Biochimica et Biophysica Acta (BBA) Reviews on Biomembranes 1972-04-18;265(2):169186. doi:10.1016/0304-4157(72)90001-9. ISSN 03044157. PMID 4555469.

52. Datta De B, Bisset NG. "Alkaloids of Strychnosignatii". Planta Medica 1990;56(1):133. doi:10.1055/s-2006-960910. PMID 17221391.

53. List PH, Hörhammer L, eds. HagersHandbuch der pharmazeutischen Praxis (in German) (4 ed.). Springer Verlag 1979. ISBN 3-540-07738-3.

54. Berger Artur, Wachter Helmut eds. Hunnius Pharmazeutisches Wörterbuch (in German) (8 ed.). Walter de Gruyter Verlag 1998. ISBN 3-11-015793-4.

55. Yilmaz Bulent, Yilmaz Barış, Aktaş Bora Unlu, Ozan; Roach, Emir Charles. "Lesser celandine (pilewort) 
induced acute toxic liver injury: The first case report worldwide". World Journal of Hepatology 2015-0227;7(2):285-288. doi:10.4254/wjh.v7.i2.285. ISSN 1948-5182. PMC 4342611. PMID 25729484.

56. Verbraucherschutz, Bundesamtfür. List of Substances of the Competent Federal Government and Federal State Authorities: Category "Plants and plant parts" 2014-09-12. Springer. ISBN 9783319107325.

57. Lewis, Robert Alan. Lewis' Dictionary of Toxicolog 1998-03-23. CRC Press. ISBN 9781566702232.

58. Handbuch der organischen Chemie, Leopold Gmelin (in German) Mares D et al. Antimicrobial activity of protoanemonin, a lactone from ranunculaceous plants 1987;98(3):133-40. doi: 10.1007/BF00437648. PMID: 3587338

59. Antonio Macho, Concepción Lucena, Rocio Sancho, Nives Daddario, Alberto Minassi, Eduardo Muñoz, Giovanni Appendino. "Non-pungent Capsaicinoids from Sweet Pepper Synthesis and Evaluation of the Chemopreventive and Anticancer Potential." Eur. J. Nutr 2003;42:2-9.

60. Nelson AG et al., Wilderness Environ Med, Fall 2000;11:152-6.

61. Szallasi A, Blumberg PM. Vanilloid (Capsaicin) receptors and mechanisms. Pharmacology Reviews 1999;51:159-212.

62. Nagy L et al., Eur J Pharmacol 2004;500:351-369.

63. Iwai $\mathrm{K}$ et al. Roles as metabolic regulators for the nonnutrients capsaicin and capsiate, supplemented to diet. Proc. Japan Acad 2003;79B(7)207-212.

64. Kawada $\mathrm{T}$ et al., Proc Soc Exp Biol Med 1986;183:250-256.

65. Iida T et al., Neuropharmacol 2003;44:958-967.

66. Ohnuki K et al., J Nutr Sci Vitaminol 2001;47:295-298.

67. "Flavonoids". Linus Pauling Institute, Oregon State University, Corvallis, OR. 2020. Retrieved 6 October 2020.

68. EFSA Panel on Dietetic Products, Nutrition and Allergies (NDA). "Scientific Opinion on the substantiation of health claims related to various food(s)/food constituent(s) and protection of cells from premature aging, antioxidant activity, antioxidant content and antioxidant properties, and protection of DNA, proteins and lipids from oxidative damage pursuant to Article 13(1) of Regulation (EC) No 1924/20061". EFSA Journal 2010;8(2):1489. doi:10.2903/j.efsa.2010.1489.

69. Ravishankar D, Rajora AK, Greco F, Osborn HM. "Flavonoids as prospective compounds for anti-cancer therapy". The International Journal of Biochemistry \& Cell Biology 2013;45(12):2821-2831. doi:10.1016/j.biocel.2013.10.004. PMID 24128857.

70. Manach C, Mazur A, Scalbert A. "Polyphenols and prevention of cardiovascular diseases". Current Opinion in Lipidology 2005;16(1):77-84. doi:10.1097/00041433-200502000- 00013. PMID 15650567.

71. Babu PV, Liu D, Gilbert ER. "Recent advances in understanding the anti-diabetic actions of dietary flavonoids". The Journal of Nutritional Biochemistry. 2013;24(11):1777-1789.

doi:10.1016/j.jnutbio.2013.06.003. PMC 3821977. PMID 24029069.

72. Ferretti G, Bacchetti T, Masciangelo S, Saturni L.
"Celiac Disease, Inflammation and Oxidative Damage: A Nutrigenetic Approach". Nutrients 2012;4(12):243257. doi:10.3390/nu4040243. PMC 3347005. PMID 22606367. 55.

73. Stauth D. "Studies force new view on biology of flavonoids". EurekAlert!, Adapted from a news release issued by Oregon State University, 2007.

74. Romagnolo DF, Selmin OI. "Flavonoids and cancer prevention: a review of the evidence". J Nutr Gerontol Geriatr 2012;31(3):206-38 doi:10.1080/21551197.2012.702534. PMID 22888839.

75. Wang X, Ouyang YY, Liu J, Zhao G. "Flavonoid intake and risk of CVD: a systematic review and meta-analysis of prospective cohort studies". The British Journal of Nutrition 2014;111(1):1-11. doi:10.1017/S000711451300278X. PMID 23953879.

76. Nehlig A, Daval JL, Debry G. "Caffeine and the central nervous system: mechanisms of action, biochemical, metabolic and psychostimulant effects". Brain Research. Brain Research Reviews 1992;17(2):139-70. doi:10.1016/0165-0173(92)90012-B. PMID 1356551. S2CID 14277779.

77. Burchfield G. Hopes M (ed.). "What's your poison: caffeine". Australian Broadcasting Corporation. Archived from the original on 26 July 2009. Retrieved 1997.

78. "Caffeine". DrugBank. University of Alberta. Retrieved 2014.

79. "All Octopuses Are Venomous, Study Says". Animals. 2009-04-17. Retrieved 2019-08-06.

80. NOVA. Cuttlefish: Kings of Camouflage. (television program) NOVA, PBS, 2007.

81. "NOVA Online | Teachers | Viewing Ideas | Kings of Camouflage | PBS". www.pbs.org. Retrieved 2019-0806.

82. Derby Charles D, Kicklighter Cynthia E, Johnson PM, Zhang Xu. "Chemical Composition of Inks of Diverse Marine Molluscs Suggests Convergent Chemical Defenses". Journal of Chemical Ecology 2007-0501;33(5):1105-1113. doi:10.1007/s10886-007-9279-0. ISSN 0098- 0331. PMID 17393278. S2CID 92064.

83. "NOVA | Kings of Camouflage | Anatomy of a Cuttlefish (non-Flash) | PBS". www.pbs.org. Retrieved 2019-04-15.

84. Dierks S. "Gold MSDS". Electronic Space Products International. Archived from the original on 2006.

85. Kent JT, repertory of homoeopathic Materia medica, chapter-nose, $9^{\text {th }}$ impression, 2015.

86. Pathak SR. A concise repertory of homoeopathic medicines, alphabetically arranged, $4^{\text {th }}$ edition 2005 , revised \& corrected, 16 ${ }^{\text {th }}$ impression2017, B. Jain Publishers (P) ltd. 